\title{
Study of kerf geometry of multilayers materials in abrasive water jet cutting process
}

\author{
Bogdan Barabas ${ }^{1, *}$ and Andrea Deaconescu ${ }^{1}$ \\ ${ }^{1}$ Transilvania University of Brasov, Faculty of Technological Engineering and Industrial \\ Management, Department of Engineering and Industrial Management, Romania
}

\begin{abstract}
The use of abrasive jet cutting in case of multilayers materials, shows particularities and difficulties, due to different hardness and thickness of layers. This paper studies changes, occurred in the kerf geometry at passing of abrasive particles, through layers with different hardness and aims to establish a link between hardness and thickness of the layers and kerf geometry because processing accuracy is determined by the geometry of the cut. Thus, is proposed a novel algorithm based on minimization of angle of kerf, for optimization a cutting process in abrasive water jet technology, which can be utilized for materials with different hardness in layers. Direct effect of optimization of cutting consist in increasing efficiency, dimensional precision, traverse velocity, and decreasing the amount of used abrasive garnet.
\end{abstract}

\section{Introduction}

The cutting of welded, thermochemical treated or multilayer material shows problems in establishing the correct machining, with direct consequences on the cutting process. Form of resulting kerf to the hydro abrasive jet crossing, hence the geometry of the finished part, is influenced by different hardness of layers of cutting material, is influenced by jet characteristics (pressure, mass flow, traverse speed, abrasive type) and by the technological characteristics of the abrasive water jet cutting process (nozzle diameter, focusing tube length, distance to the work piece).

Modeling abrasive water jet cutting process of multilayer materials it is influenced by position of layers in material, appearing micro cracks to crossing limit in rough layer, breaks or micro compactions in layer with lower hardness. The elimination of these phenomena does not have an analytical solution this time, optimization of cutting jet cutting of multilayer materials are made experimental. The study of the jet behavior and the trajectory of the abrasive particles while abrasive jet cutting, has proved a complex process in three stages, before impact, during impact and during abrasive cutting. The presence of layers with different hardness increases the complexity of phenomenon modeling, by adding points to change behavior during each passage. In the context of penetration of new branches in the sphere of unconventional technologies such as milling and turning with

\footnotetext{
* Corresponding author: barabas.bogdan.florin@unitbv.ro
} 
abrasive jet, control of geometry processing becomes a normal requirement, and optimizing dimensional precision becomes a necessity.

Choosing the incorrect processing parameters results in incomplete cutting or the reverse, a too strong cutting with high consumption of abrasive and energy, leading to a too long machining time and to an unprofitable cost price. For the user of this sort of machines, the losses become significant, the optimization of process become absolutely necessary. In this purpose the present paper proposes a new algorithm for optimization the kerf geometry of multilayer material with different hardness.

\section{Theoretical consideration}

Abrasive water jet cutting process is influenced by two major factors: material properties and machining parameters. The plan of abrasive water jet process is presented in Fig. 1, [1].

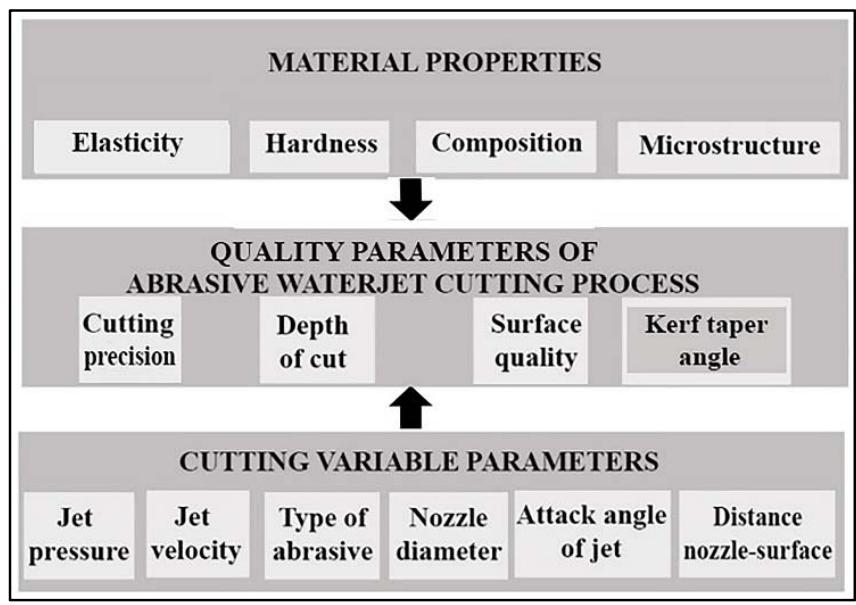

Fig. 1. Abrasive water jet cutting process.

The high speed jet is obtained by passing water at high pressure through a sapphire nozzle, applying Bernoulli's law [2-3]:

$$
p_{a t}+\frac{\rho_{a}}{2} V_{j}^{2}+\rho_{a} g h_{1}=p+\frac{\rho_{a}}{2} V_{h}^{2}+\rho_{a} g h_{2}
$$

where: $\quad p_{a t}$ is the athmospheric pressure $[\mathrm{Pa}]$;

$\mathrm{p}$ is the fluid pressure at the entrance to the nozzle $[\mathrm{Pa}]$;

$\rho_{\mathrm{a}}$ is water density $\left[\mathrm{kg} / \mathrm{m}^{3}\right]$;

$\mathrm{V}_{\mathrm{j}}$ is the velocity of the jet at the exit of the nozzle orifice $[\mathrm{m} / \mathrm{s}]$;

$\mathrm{V}_{\mathrm{h}}$ is the flow velocity of high pressure water $[\mathrm{m} / \mathrm{s}]$;

$\mathrm{h}_{1}=\mathrm{h}_{2}$ is the distance to the reference plane [mm].

Considering: $h_{1}=h_{2}, V_{j}>>V_{h}, p>>p_{a t}$, relation (1) become:

$$
\begin{gathered}
\frac{\rho_{a}}{2} V_{j}^{2}=p \\
V_{j}=\sqrt{\frac{2 p}{\rho_{a}}}
\end{gathered}
$$

In reality, losses due to the friction, due to the occurrence of turbulent flow and due to compressibility of water, changes the relationship (3):

$$
V_{j}=\mu \sqrt{\frac{2 p}{\rho_{a}}}
$$


where $\mu$ is a factor specific to each installation dependent on friction losses, turbulence, compressibility, the water pressure and the nozzle shape [4-6].

After embedding abrasive and air, in mixing chamber and after directing the formed jet by the focusing tube, speed can be appreciated by applying the law of conservation of moments:

$$
\begin{gathered}
\sum \frac{\mathrm{dm}}{\mathrm{dt}} \cdot \mathrm{V}_{(\text {initial })}=\sum \frac{\mathrm{dm}}{\mathrm{dt}} \cdot \mathrm{V}_{(\text {final })} \\
\frac{d m_{w}}{d t} \cdot V_{j}=\frac{d m_{\text {air }}}{d t} \cdot V_{f}+\frac{d m_{w}}{d t} \cdot V_{f}+\frac{d m_{a b r}}{d t} \cdot V_{f}
\end{gathered}
$$

Considering insignificant air mass and the speed of the abrasive particles and the molecules of water equal to the output speed of the focusing tube $\mathrm{V}_{\mathrm{f}}$, result:

$$
\begin{gathered}
\frac{\mathrm{dm}_{\mathrm{w}}}{\mathrm{dt}} \cdot \mathrm{V}_{\mathrm{j}}=\left(\frac{\mathrm{dm}_{\mathrm{w}}}{\mathrm{dt}}+\frac{\mathrm{dm}_{\mathrm{abr}}}{\mathrm{dt}}\right) \cdot \mathrm{V}_{\mathrm{f}} \\
\mathrm{V}_{\mathrm{f}}=\frac{\frac{\mathrm{dm}_{\mathrm{w}}}{\mathrm{dt}}}{\left(\frac{\mathrm{dm}_{\mathrm{w}}}{\mathrm{dt}}+\frac{\mathrm{dm}_{\mathrm{abr}}}{\mathrm{dt}}\right)} \cdot V_{j}
\end{gathered}
$$

The kerf taper angle $\varphi$ (Fig. 2) is a parameter that can be controlled with optimization of other parameters [7].

$$
\varphi=f\left(V_{f}, \frac{d_{j}}{V_{t}}, h, \frac{\mathrm{dm}_{\mathrm{abr}}}{\mathrm{dt}}, d_{j}, E, H_{R}\right)
$$

where: $\quad \varphi$ is kerf taper angle $\left[{ }^{0}\right]$;

$\mathrm{V}_{\mathrm{f}}$ is the velocity of the jet at the place of impact $[\mathrm{m} / \mathrm{s}]$;

$\mathrm{V}_{\mathrm{t}}$ is the traverse speed of abrasive water jet $[\mathrm{m} / \mathrm{s}]$;

$\mathrm{d}_{\mathrm{j}}$ is diameter of jet at output of focusing tube [mm] ;

$\mathrm{h}$ is distance of output of focusing tube to the workpiece [mm] ;

$\mathrm{E}$ is elastic modulus [MPa].

$\mathrm{H}_{\mathrm{R}}$ is Rockwell hardness of piece [MPa]

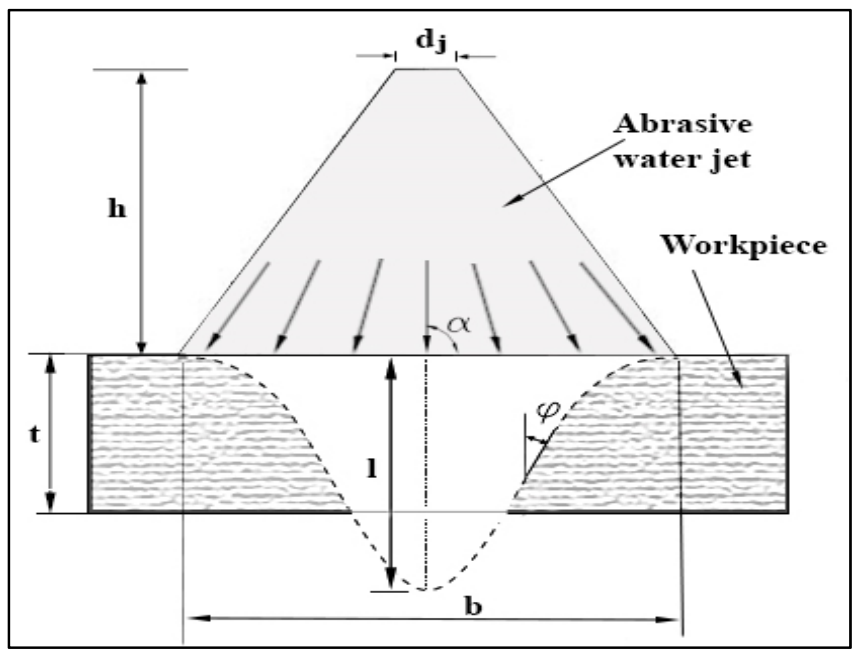

Fig. 2. The role of parameters of abrasive water jet in kerf geometry.

In the case of multilayers materials with different hardness the kerf taper angle changes value depending on the hardness of the material, switching between layers is marked by the change in angle value. 
Applying relation (9) is obtained:

$$
\begin{gathered}
\varphi_{1}=f\left(V_{f}, \frac{d_{j}}{V_{t}}, h, \frac{\mathrm{dm}_{\mathrm{abr}}}{\mathrm{dt}}, d_{j}, E_{1}, H_{R 1}\right) \\
\varphi_{2}=f\left(V_{f}, \frac{d_{j}}{V_{t}}, h, \frac{\mathrm{dm}_{\mathrm{abr}}}{\mathrm{dt}}, d_{j}, E_{2}, H_{R 2}\right)
\end{gathered}
$$

The two material parameters, $\mathrm{E}$ and $\mathrm{H}_{\mathrm{R}}$ contributes directly to the cutting taper angle, determining geometric shape modification of cutting parts. Increase of precision of processing multilayers materials, becomes an important issue and process optimization is needed.

\section{Modeling of kerf geometry variation in case of cutting of multilayers materials with different hardness}

Increased hardness leads to increased taper angle (Fig.3) Considering $\mathrm{H}_{\mathrm{R} 1}>\mathrm{H}_{\mathrm{R} 2}$ and $\varphi_{1}>\varphi_{2}$ results that minimizing $\varphi_{1}$, optimal selection of parameters that influence the process, can lead to a significant increase quality of geometry of resulting parts. Thus decreasing of the distance $\mathrm{h}$ lead to a minimum of kerf taper angle.
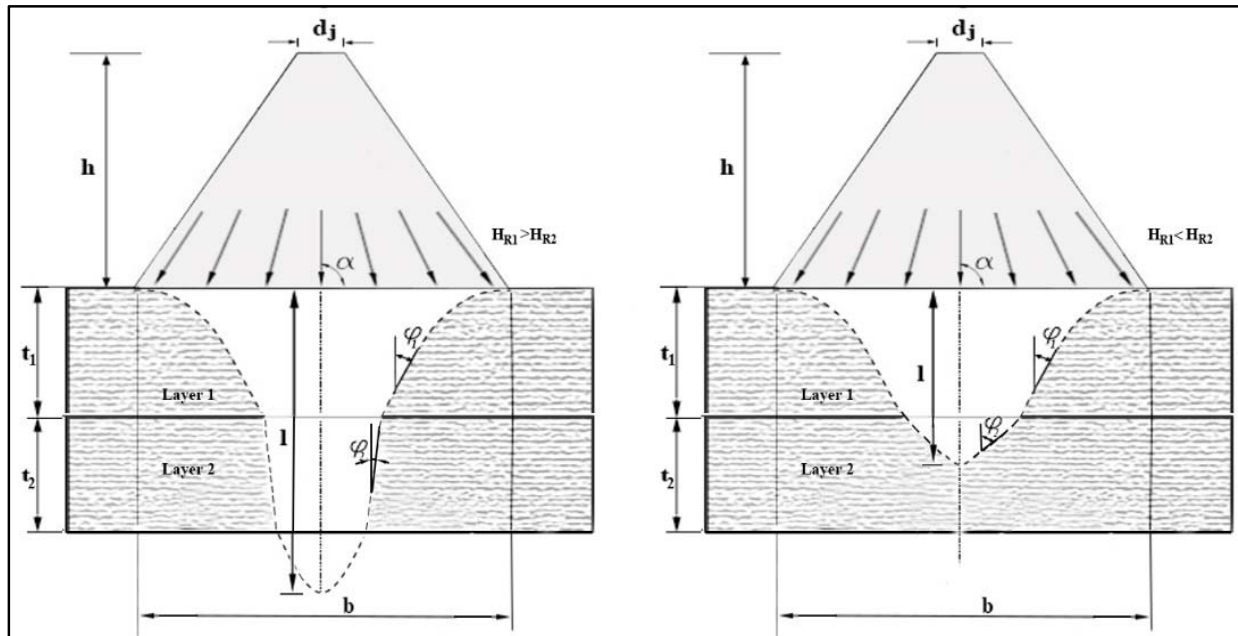

Fig. 3. The kerf taper angle in case of multilayer materials with different hardness $\left(H_{R 1}>H_{R 2}\right.$ in left and $\mathrm{H}_{2}>\mathrm{H}_{\mathrm{R} 1}$ in right of image).

Kerf geometry optimization is done considering the top layer hardness, whose taper angle is greater than the taper angle of softened layer. Initial condition in calculation algorithm is cutting condition (punching shear) of the thickness of the material $1>t$ where $\mathrm{t}=\mathrm{t}_{1}+\mathrm{t}_{2}$.

Generally it is recommended that the layer with higher hardness to be cut first, but are cases (Fig. 3 right) when this could not be applied and taper angle grows stronger.

For process modelling, were considered the demands for type processing $H_{R}, E, h, V_{f}$ si $\mathrm{dm}_{\text {abr }} / \mathrm{dt}$. Both, the speed of impact, and abrasive flow mass have less influence [8] and hardness and elasticity are material factors.

Distance $h$, of the head of focusing tube to the work piece, choose the minimum (1-2 $\mathrm{mm}$ ) depending on the cutting surface [9]. 


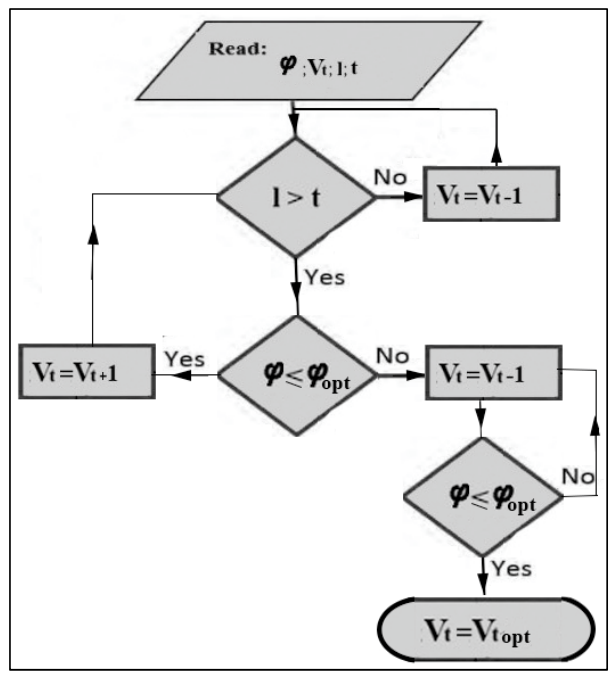

Fig. 4. Determining optimum traverse speed in order to obtain an optimum taper angle.

The algorithm presented in Fig.4, allows choosing a traverse speed that contribute to achieving a taper angle in accordance with the requirements of precision of the piece, namely $\varphi_{\text {opt }}$. The initial condition is complete cutting of material and optimum taper angle is chosen so that it ensure accuracy of workpiece. The traverse speed $V_{t}$ is increased or decreased so that $1>t$ and $\varphi \leq \varphi_{\text {opt }}$

For experiments were chosen a material composed of two plates rectified of $15 \mathrm{NiCr} 13$ alloy steel carburized at 63 HRC. Dimensions of cutting are: thickness $t=t_{1}+t_{2}=10 \mathrm{~mm}$, where $\mathrm{t}_{1}=\mathrm{t}_{2}=5 \mathrm{~mm}$ and length of cutting, $\mathrm{L}=60 \mathrm{~mm}$.

Table 1. Values of taper angle for variable process parameters.

\begin{tabular}{|c|c|c|c|c|c|c|c|}
\hline $\begin{array}{l}\text { Test } \\
\text { no. }\end{array}$ & $\begin{array}{c}\text { Pressure } \\
{[\mathrm{MPa}]}\end{array}$ & $\begin{array}{c}\text { Orifice } \\
\text { diameter } \\
{[\mathrm{mm}]}\end{array}$ & $\begin{array}{c}\text { Type } \\
\text { of } \\
\text { garnet } \\
\text { [Mesh] }\end{array}$ & $\begin{array}{c}\text { Measured } \\
\text { abrasive } \\
\text { flow rate } \\
{[\mathrm{kg} / \mathrm{min}]}\end{array}$ & $\begin{array}{c}\text { Used } \\
\text { abrasive } \\
{[\mathrm{Kg}]}\end{array}$ & $\begin{array}{c}\text { Operation } \\
\text { time } \\
{[\mathrm{min}]}\end{array}$ & $\begin{array}{c}\text { Calculated } \\
\text { taper } \\
\text { angle } \\
\text { [degrees] }\end{array}$ \\
\hline \multirow{2}{*}{1.} & \multirow{8}{*}{345} & \multirow{4}{*}{0.28} & \multirow{2}{*}{80} & \multirow{2}{*}{0.34} & \multirow{2}{*}{0.43} & 1.358 & 0.772 \\
\hline & & & & & & 1.525 & 0.572 \\
\hline \multirow{2}{*}{2.} & & & \multirow{2}{*}{100} & \multirow{2}{*}{0.405} & \multirow{2}{*}{0.49} & 1.316 & 0.651 \\
\hline & & & & & & 1.475 & 0.467 \\
\hline \multirow{2}{*}{3.} & & \multirow{4}{*}{0.08} & \multirow{2}{*}{80} & \multirow{2}{*}{0.05} & \multirow{2}{*}{0.38} & 9.58 & 0.496 \\
\hline & & & & & & 11.06 & 0.378 \\
\hline \multirow{2}{*}{4.} & & & \multirow{2}{*}{100} & \multirow{2}{*}{0.081} & \multirow{2}{*}{0.59} & 7.38 & 0.412 \\
\hline & & & & & & 9.10 & 0.355 \\
\hline \multirow{2}{*}{5.} & \multirow{8}{*}{180} & \multirow{4}{*}{0.28} & \multirow{2}{*}{80} & \multirow{2}{*}{0.28} & \multirow{2}{*}{1.19} & 4.33 & 0.811 \\
\hline & & & & & & 6.12 & 0.593 \\
\hline \multirow{2}{*}{6.} & & & \multirow{2}{*}{100} & \multirow{2}{*}{0.335} & \multirow{2}{*}{1.29} & 3.96 & 0.795 \\
\hline & & & & & & 5.82 & 0.588 \\
\hline \multirow{2}{*}{7.} & & \multirow{4}{*}{0.08} & \multirow{2}{*}{80} & \multirow{2}{*}{0.022} & \multirow{2}{*}{0.73} & 33.2 & 0.612 \\
\hline & & & & & & 42.6 & 0.524 \\
\hline \multirow{2}{*}{8.} & & & \multirow{2}{*}{100} & \multirow{2}{*}{0.058} & 136 & 22.5 & 0.573 \\
\hline & & & & & 1.36 & 30.4 & 0.402 \\
\hline
\end{tabular}


Setting the AWJ machine, Maxiem 1530 from Omax Corporation, has been executed by changing water pressure provided by the pump for the maximum value $\mathrm{p}=345 \mathrm{MPa}$ to $\mathrm{p}=$ $180 \mathrm{MPa}$. Samples were executed with two pressures for each type of abrasive. Abrasive flow rate was measured in Test Mode for $\mathrm{t}=5 \mathrm{~min}$ and the obtained value was introduced in the configuration window. Operation time is setting for two values of thickness. The taper angle was calculated as the average of three values measured on the same sample in harder layer.

\section{Conclusions}

The experiments shown in table 1 leads to the conclusion that increase of operation time, has positive influence to kerf geometry in terms of minimization of kerf taper angle. Increase of operation time, so decrease of traverse speed $V_{t}$ causes an increase in processing cost, results that an optimal choice of traverse speed is absolutely necessary.

Develop a correct algorithm, allowed to achieve in few steps an optimal value for traverse speed. Direct effect of optimization of cutting consist in increasing of efficiency, increasing of the traverse velocity, decreasing the amount of abrasive garnet used. Optimization results in increased dimensional precision and increased surface quality.

The wide use of cutting jet do occur in the cutting process, a growing number of materials such as multilayer materials or welded materials. This research opens the door to extensive research in this area, in order to optimize cutting abrasive water jet for different types of multilayer materials with variable hardness.

\section{References}

1. B. Barabas, A. Fota, S.A. Barabas, INTECH 2015, 142-146 (2015).

2. D. J. Thomas, J. Man. Proc. 15, 355-363 (2013).

3. A. Lebar, M. Junkar, J. Mod. Sim. Mat. Sci. Eng., 12, 1159-1170 (2004).

4. J. Wang, Int. J. Mec. Sci. 49, 306-316 (2007).

5. V. Gupta, P. M. Pandey, M. Garg, R. Khanna, N. K. Batra, Proc. Mat. Sci. 6, 140-149 (2014).

6. M. Gent, M. Menéndez, S. Torno, J. Torano, A. Schenk, Wear J., 284, 43- 51 (2012).

7. D. K. Shanmugam, S. H. Masood, J. Mater. Process Technol. 209, 3887-3893 (2009).

8. S. A. Barabas, A. Florescu, G. Calefariu, F. Sarbu, Adv. Mater. Res., 1128, 293-303 (2015).

9. D. Trainer, Int., J. Multi. Flow, 81, 77-87 (2016). 